\title{
Photosensitive Fluorescent Dye Contributes to Phototoxicity and Inflammatory Responses of Dye-doped Silica NPs in Cells and Mice
}

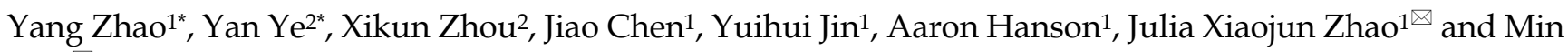 \\ $\mathrm{Wu}^{2 \bowtie}$ \\ 1. Department of Chemistry, School of Arts and Sciences; \\ 2. Department of Biochemistry and Molecular Biology, School of Medicine and Health Sciences, University of North Dakota, Grand Forks, \\ ND58202, USA. \\ * These authors contributed equally to this work.
}

$\square$ Corresponding authors: jzhao@chem.und.edu, or min.wu@med.und.edu.

(C) Ivyspring International Publisher. This is an open-access article distributed under the terms of the Creative Commons License (http://creativecommons.org/ licenses/by-nc-nd/3.0/). Reproduction is permitted for personal, noncommercial use, provided that the article is in whole, unmodified, and properly cited.

Received: 2013.09.13; Accepted: 2014.01.27; Published: 2014.02.12

\begin{abstract}
Dye-doped fluorescent silica nanoparticles provide highly intense and photostable fluorescence signals. However, some dopant dye molecules are photosensitive. A widely-used photosensitive fluorescent dopant, RuBpy, was chosen to systematically investigate the phototoxicity of the dye-doped silica nanoparticles (NPs). We investigated cell viability, DNA damage, and Reactive Oxygen Species (ROS) levels in alveolar macrophages using the dye-doped NPs with or without irradiation. Our results showed that the RuBpy-doped silica NPs could induce significant amount of ROS, DNA damage, apoptosis and impaired proliferation in $\mathrm{MH}-\mathrm{S}$ cells. In vivo studies in mice showed that RuBpy-doped silica NPs induced significant inflammatory cytokine production and lowered expression in signaling proteins such as ERKI/2 and NF-KB as well as increased lung injury determined by myeloperoxidase and lipid peroxidation. Strikingly, we also found that both RuBpy alone and NPs induced systemic signaling activation in the kidney compared to the liver and lung where showed highly selective signaling patterns, which is more pronounced than RuBpy-doped silica NPs. Moreover, we discovered a critical biomarker (e.g., HMGBI) for silica NPs-induced stress and toxicity and demonstrated differentially-regulated response patterns in various organs. Our results indicate for the first time that the RuBpy-doped silica NPs may impose less inflammatory responses but stronger thermotherapeutic effects on target cells in animals than naked NPs in a time- and dose-dependent manner.
\end{abstract}

Key words: Silica NPs, tris(2,2'-bipyridyl)dichlororuthenium(II) hexahydrate (RuBpy), phototoxicity, fluorescence, reactive oxygen species.

\section{Introduction}

The rapid progress of nanoscience and nanotechnology research permits the birth of a wide variety of novel nanomaterials. Currently, fluorescent nanoparticles (NPs) are one of the most attractive optical probes in bioimaging and bioanalysis due to their unique optical properties and high surface-to-volume ratio. In comparison with traditional fluorescence labeling materials, fluorescent nanomaterials significantly improve the specificity and sensitivity of bioanalysis such as targeting imaging and molecular interactions $[1,2]$. These advantages allow the direct and rapid detection of various biomolecules, even in a 
trace amount. Up to date, several effective fluorescent nanomaterials have been developed including quantum dots (QDs) [3, 4], liposomes [5], and various nanostructures with surface modifications such as dye-doped NPs [6-8]. The dye-doped NPs may be an attractive fluorescent nanomaterial because thousands of dye molecules can be doped in a single nanoparticle thereby emitting intensive fluorescence signals. By conjugating molecular recognition reagents and different dyes to the nanoparticle surface, the NPs may gain an excellent signaling capability to sensitively and specifically determine trace amounts of biological targets.

To date, fluorescent NPs have been used to track biological targets including tissues, living cells, DNAs, and protein molecules [9-13]. With ever increasing usages of these NPs, their potential toxicity to living systems has become a major concern. To address this concern, a number of toxicological studies have been conducted with fluorescent nanomaterials [14-18]. The toxicity of the dye-doped NPs may be attributed to their composites, structures, and morphology [19-22]. Previous studies on nanoparticle toxicity have shown that size, shape and surface properties of NPs are key factors that determine whether or not the particles can eventually enter and retain inside living systems [21, 23-25]. In addition, the toxicity varies with the type of cell lines. Cancer cell lines (A549, MKN-28) were more resistant to silica-based fluorescent NPs than normal cell lines (MRC-5, WS1 and CCD-966sk) [26]. Similarly, our previous study showed that A549 cells were more resistant to the treatment of silica NPs than were macrophages [27]. In general, foreign materials invade a living system through three pathways, namely the respiratory tract, the gastrointestinal tract, and by skin contact. The toxicity of airborne ultrafine particles and certain engineered nanomaterials have been well documented [28-32], with colloidal silica generally being accepted as either a nontoxic or low toxic material [33, 34]. Thus, silica-based dye-doped NPs appear to be more popular than other dye-doped NPs for biomedical research.

The dopants, dye molecules, in general, have little effect on the toxicity of dye-doped NPs because they are isolated from the natural environment [33, 35]. However, if the dopants are photosensitizers, they may have increased toxicity of the NPs under irradiation. Irradiation is usually required for applications of dye-doped NPs as fluorescent labeling reagents in the biological field. Therefore, studies of phototoxicity with dye-doped nanomaterials are necessary to expand and improve their applications in bioimaging and bioanalysis.
Tris(2,2'-bipyridyl) ruthenium(II) chloride (RuBpy), is a widely-used fluorescent dopant for making silica-based fluorescent nanomaterials. There is evidence showing that RuBpy ${ }^{2+}$ can produce Reactive Oxygen Species (ROS) under irradiation [35]. However, it remains unclear whether RuBpy-doped NPs could have significant alterations in their toxicological behavior when they are under irradiation. Therefore, the RuBpy-doped fluorescent silica NPs would be a viable model for studying the phototoxicity of the dye-doped NPs to living systems.

In this study, we first investigated the potential phototoxicity of RuBpy-doped silica NPs in cultured murine alveolar macrophage (MH-S) cells. MH-S cells were chosen because in vivo biodistribution of the silica NPs showed a great accumulation of silica NPs in liver, spleen [36], and macrophage cells. Herein we evaluated ROS generation, DNA damage, and cell proliferation rates after treating the cells with dye-doped NPs and exposing irradiation. Importantly, in vivo patho-physiological impact and the relevant mechanisms with dye-doped NPs have also been evaluated in C57BL6 mice.

\section{Materials and Methods}

\section{Materials}

Tris(2,2'-bipyridyl)dichlororuthenium(II) hexahydrate (RuBpy) was purchased from Acros Organics (MW 748.63, Belgium). Acetic acid, polyoxyethylene isooctylphenylether [triton X-100, 4- $\left(\mathrm{C}_{8} \mathrm{H}_{17}\right) \mathrm{C}_{6} \mathrm{H}_{4}$ $\left.\left(\mathrm{OCH}_{2} \mathrm{CH}_{3}\right)_{10}-\mathrm{OH}\right]$ and $98 \%$ Tetraethylorthosilicate (TEOS) were purchased from Aldrich Chemical Co. Inc. (Milwaukee, WI). Cyclohexane, $n$-hexanol, acetone, and ammonium hydroxide (28-30\%) were obtained from Fisher Scientific Co. (Pittsburgh, PA). Hydrogen peroxide $\left(\mathrm{H}_{2} \mathrm{O}_{2}\right)$ and DMSO were purchased from Sigma-Aldrich (St. Louis, MO). Phosphate buffered saline (PBS) tablets was obtained from MP Biomedicals (Solon, OH). Vybrant ${ }^{\circledR}$ apoptosis assay kit was purchased from the Molecular Probes (Grand Island, NY). Celltiter $96^{\circledR}$ non-radioactive cell proliferation assay kit was obtained from Promega (Madison, WI). Nitroblue Tetrazolium (NBT) solution was purchased from Calbiochem (Billerica, MA). Sodium dodecyl sulfate (SDS) was purchased from Invitrogen (Grand Island, NY). The murine alveolar macrophage MHS cell line was purchased from ATCC (Manassas, VA). The cell culture medium was made of GIBCO RPMI 1640 medium (Invitrogen, NY) with $5 \%$ newborn bovine serum (NBS, purchased from Hyclone, Logan, UT), 2 mM HEPES buffer (pH7.2) and $1 \%$ penicillin streptocycin (Invitrogen). Water used in the all experiments was ultra-purified (18.3 $\mathrm{M} \Omega \cdot \mathrm{cm}$ ) using a Milli-Q Millipore system. 
Instruments. A Carl Zeiss 510 META Confocal Fluorescence Microscope (Carl Zeiss MicroImaging, Inc, Thornwood, NY) was employed for taking fluorescence images. A Hitachi 7500 Transmission Electron Microscope (TEM) and a Hitachi 4700 Field Emission Scanning Electron Microscope (SEM) were used to characterize the shape and the size of synthesized NPs. A Multiskan spectrum high performance spectrophoto plate reader was used to measure the UV-vis absorption (Thermo Electron Corporation). A Jobin Yvon Horiba Flourolog-3 spectrofluorometer was employed to measure the fluorescence emission and excitation. An Ushio xenon short arc lamp was used as the light source in this spectrofluorometer. This instrument provides an excitation range of $240-600 \mathrm{~nm}$ and an emission range of $290-850 \mathrm{~nm}$. An Eppendorf5804 centrifuge was used for separation of NPs from the solution in the synthesis process.

Synthesis and Characterization of the Fluorescence Silica NPs. The NPs were synthesized using a reverse microemulsion method $[37,38]$. Briefly, a microemulsion solution was prepared by mixing 7.50 $\mathrm{mL}$ of cyclohexane, $1.80 \mathrm{~mL}$ of $n$-hexanol, and $1.77 \mathrm{~mL}$ of Triton X-100. After stirring of this mixture for 20 min, $80 \mu \mathrm{L}$ of $0.01 \mathrm{M}$ RuBpy solution and $400 \mu \mathrm{L}$ of water were added to the mixture to form a microemulsion. Finally, $100 \mu \mathrm{L}$ of TEOS and $60 \mu \mathrm{L}$ of $\mathrm{NH}_{4} \mathrm{OH}$ were added to the solution to initiate the hydrolysis of the TEOS. The reaction was allowed to proceed for $24 \mathrm{~h}$ under continuous stirring. Afterwards, the fluorescent silica NPs were formed. To avoid NPs aggregation, the surface of silica NPs were modified with carboxyl groups by adding a post-coating reagent. A $50 \mu \mathrm{L}$ aliquot of $42 \%$ 3-(trihydrosilyl)propylmethyl-phosphonate monosodium salt was added with an additional $50 \mu \mathrm{L}$ of TEOS. This mixture was allowed to react for $24 \mathrm{~h}$ with continuous stirring. The NPs were released from the microemulsion by adding $20 \mathrm{~mL}$ of acetone to the microemulsion. The NPs were washed with ethanol twice and with water once. After air-dried, the NPs were resuspended in the PBS buffer at the concentration of $1.0 \mathrm{mg} / \mathrm{mL}$. The size and morphology of the fluorescent silica NPs were characterized using electron microscopes [39].

Treatment of Cells with the NPs and Irradiation. Approximately $1.0 \times 10^{6} \mathrm{MH}-\mathrm{S}$ cells were seeded in each well of a 96-well plate and cultured for $24 \mathrm{~h}$ at $37{ }^{\circ} \mathrm{C}$. Then a $100 \mu \mathrm{L}$ aliquot of the NPs in pH 7.0 PBS buffer was added to the cell culture plate for incubation over $2 \mathrm{~h}$. The final concentrations of NPs in the cell culture medium ranged from $1 \times 10^{-4} \mathrm{mg} / \mathrm{mL}$ to $0.50 \mathrm{mg} / \mathrm{mL}$ (equivalent to $10^{8}$ to $5 \times 10^{11} \mathrm{NPs} / \mathrm{mL}$ ). The negative control cells were treated with the cell culture medium without NPs. During all these treat- ments, the cells were incubated at $37{ }^{\circ} \mathrm{C}$ in a $5 \% \mathrm{CO}_{2}$ and humidified atmosphere.

After the NPs treatment, a blue light emitting diode (LED) lamp (OptiLED Inc.) was employed for irradiation of the NPs in the incubator. Followed different time periods of irradiation, several biological assays were proceeded to test the toxicity as below.

Nitroblue Tetrazolium (NBT) Assay. The NBT assay was used to determine the production of ROS in the living cells [40]. The cells were treated with NPs for $2 \mathrm{~h}$. Then a $5 \mu \mathrm{L}$ aliquot of $3 \mu \mathrm{g} / \mathrm{mL}$ NBT solution was added to the cell culture medium and the irradiation was placed onto the solution immediately for different time periods. After the irradiation, the formazan product was solubilized by $100 \mu \mathrm{L}$ stop solution $[10 \%$ sodium dodecyl sulfate (SDS) and $10 \%$ dimethyl sulfoxide (DMSO) in PBS], and its absorbance at $560 \mathrm{~nm}$ was measured using a 96-well plate reader.

Cell Proliferation Assay [3-(4,5-Dimethylthiazol-2-yl)-2,5-diphenyltetrazolium Bromide assay]. Proliferation rates of the cells were evaluated spectrophotometrically by measuring the extent of reduction of a tetrazolium salt, 3-(4,5-dimethylthiazol2-yl)-2,5-diphenyltetrazolium bromide (MTT), to formazan by succinic dehydrogenase as described previously [41]. Briefly, a premixed optimized dye solution was added to the plate wells, and then, the cells were incubated at $37^{\circ} \mathrm{C}$ for $4 \mathrm{~h}$. The formazan product was solubilized, and its absorbance at $570 \mathrm{~nm}$ was measured using a 96-well plate reader. Wells with RuBpy-doped NPs alone were used as blank control.

Trypan Blue Assay. To measure the cell death rate, trypan blue dye was used as described previously [39]. The cells were first treated with NPs and followed by the irradiation over different time periods. The cells were then dissociated from the bottom of the plate by trypsin, and were resuspended in a 96-well plate in the cell culture medium. Then a $20 \mu \mathrm{L}$ aliquot of the trypan blue dye was added to each well. The viable cell amount was counted using a hemocytometer. The viability values were derived by comparing the samples with the negative control.

Comet Assay. The integrity of DNAs in the living cells was detected using the comet assay as described previously [42]. The cells were first treated with NPs. After irradiation for various time periods, both the control cells and the NPs-treated cells were washed and resuspended in $\mathrm{Ca}^{2+}$ and $\mathrm{Mg}^{2+}$ free PBS solution. The cell suspension was mixed with liquefied agarose at a ratio of 1:10 (v/v). A small aliquot of this mixture was immediately transferred onto the slide from Trevigen (comet assay kit). After cell lysis at $4{ }^{\circ} \mathrm{C}$, slides were treated with alkali solution $[0.3 \mathrm{M}$ $\mathrm{NaOH}, 1 \mathrm{mM}$ ethylenediaminetetraacetic acid 
(EDTA)] for $60 \mathrm{~min}$ to unwind the double-stranded DNA. Slides were electrophoresed at $1 \mathrm{~V} / \mathrm{cm}$ for 10 min and then stained with SYBR green dye after they were observed under a confocal microscope (Carl Zeiss MicroImaging). The comet tail length was defined as the distance between the leading edge of the nucleus and the end of the tail. At least 75 determinations were performed for each sample using the CometScore software.

Vybrant Apoptosis Assay. MH-S cells were treated with NPs or various controls in a glass-bottomed plate for 24 hours. Afterwards, the fluorescent probe YO-PRO-1 dyes (Molecular Probes, Grand Island, NY) were loaded onto the plate [43]. After 5 min incubation, the cells were imaged under a Zeiss confocal fluorescence microscope. Living cells showed no fluorescence signals while apoptotic cells were stained by the green $\mathrm{YO}-\mathrm{PRO}^{\circledR}-1$ dye.

Flow Cytometry Assay. MH-S cells were treated with NPs or various controls in a glass-bottomed plate for 24 hours. Apoptotic cells were stained by Annexin V-FITC-stained cells and analyzed by flow cytometry (BD Biosciences, San Jose, CA) [44].

Animals and Treatment. For the in vivo toxicity study, male C57BL6 mice with weight of 20-25 g (6 weeks old) were obtained from Charles River (Wilmington, MA), and maintained in the University of North Dakota Animal Center. They were group-housed and maintained with free access to water and diet. All animal operations were in accord with the institutional animal use and care regulations, according to the approved protocol No. 1204-4 and 1204-5. The mice were treated with RuBpy-doped silica NPs via intranasal instillation similarly performed as described previously [41, 45]. The instillation dose of silica NPs is $0.5 \mathrm{mg}$ in PBS buffer. The mice received PBS alone were used as a control. After 7 days of treatment, the animals were euthanized with injection of ketamine $(45 \mathrm{mg} / \mathrm{kg}$ ) and the lung, spleen, and kidney were removed for various analyses. Animals (5 mice/group) were also treated with or without different silica NPs under irradiation for $6 \mathrm{~h}$ with a blue light emitting diode (LED) lamp before sacrificing for evaluating cell signaling and phototoxicity.

Western Blotting. The lungs and cells after infection were lysed in RIPA buffer containing a protease inhibitor cocktail (Fisher), homogenized, and quantitated [46]. The lysates were boiled for $10 \mathrm{~min}$ after adding loading dye. Equal amount of each sample $(30 \mu \mathrm{g})$ was loaded onto $10 \%$ SDS-polyacrylamide minigels and electrophoresed to resolve proteins. The proteins were then transferred to nitrocellulose membranes (Santa Cruz Biotechnologies, CA) and blocked for $2 \mathrm{~h}$ at room temperature using $5 \%$ non-fat milk blocking buffer. The membranes were then incubated with the first antibodies diluted 1:1,000 in 5\% non-fat milk blocking buffer overnight at $4^{\circ} \mathrm{C}$ [47]. After washing three times with washing buffer, the membranes were incubated with horseradish peroxidase-conjugated secondary antibody (GE Amersham, Pittsburgh, PA) diluted 1:2,000 for $2 \mathrm{~h}$ at room temperature. Signals were detected using enhanced chemiluminescence detection kit (SuperSignal West Pico, Pierce).

Myeloperoxidase (MPO) Assay. The MPO assay was performed as described previously [48]. Samples were homogenized in $50 \mathrm{mM}$ hexadecyltrime-

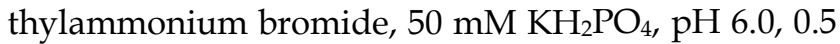
$\mathrm{mM}$ EDTA at $1 \mathrm{ml} / 100 \mathrm{mg}$ of tissue and centrifuged for $15 \mathrm{~min}$ at $12,000 \mathrm{rpm}$ at $4^{\circ} \mathrm{C}$. Supernatants were decanted, and $100 \mu \mathrm{L}$ of reaction buffer $(0.167 \mathrm{mg} / \mathrm{ml}$ O-dianisidine, $50 \mathrm{mM} \mathrm{KH} \mathrm{PO}_{4}, \mathrm{pH} 6.0,0.0005 \% \mathrm{mM}$ $\mathrm{H}_{2} \mathrm{O}_{2}$ ) were added to $100 \mu \mathrm{L}$ of sample. Absorbance was read at $460 \mathrm{~nm}$ at $2 \mathrm{~min}$ intervals. Duplicates were done for each sample and control.

Lipid Peroxidation Assay. Malondialdehyde is an end product of the lipid peroxidation and was measured using a colorimetric assay (Calbiochem) according to our previously used method [49]. Homogenized lung tissue in $62.5 \mathrm{mM}$ Tris- $\mathrm{HCl}$ ( $\mathrm{pH} 6.8$ ) supplemented with Complete Mini protease inhibitor (Roche Diagnostics, Indianapolis, IN) in equal protein amounts was used in the assay. Duplicates were done for each sample and control.

\section{Results}

\section{Penetration of RuBpy-doped Silica NPs into Cells}

To precisely study the phototoxicity of the NPs in living cells, the presence of the NPs inside the living cells is a primary requirement. Prior to the penetration study, we characterized the morphology and the dye content of the NPs. The size and shape of the synthesized NPs were examined using a Transmission Electron Microscope (TEM) (Figure 1A). The size of the produced NPs was uniform with an average diameter of $50 \pm 3 \mathrm{~nm}$. The amount of RuBpy in the NPs was measured using UV-vis spectroscopy. The results showed that $0.10 \mathrm{mg} / \mathrm{mL}$ RuBpy-doped silica NPs equaled to $1.68 \mu \mathrm{M}$ RuBpy molecules.

Next, the penetration of RuBpy-doped NPs to living cells was investigated. Considering macrophages are remarkable cells for rapidly uptaking extracellular particles and play an important role in host defense, alveolar macrophage MH-S cells were employed in our studies. 
A

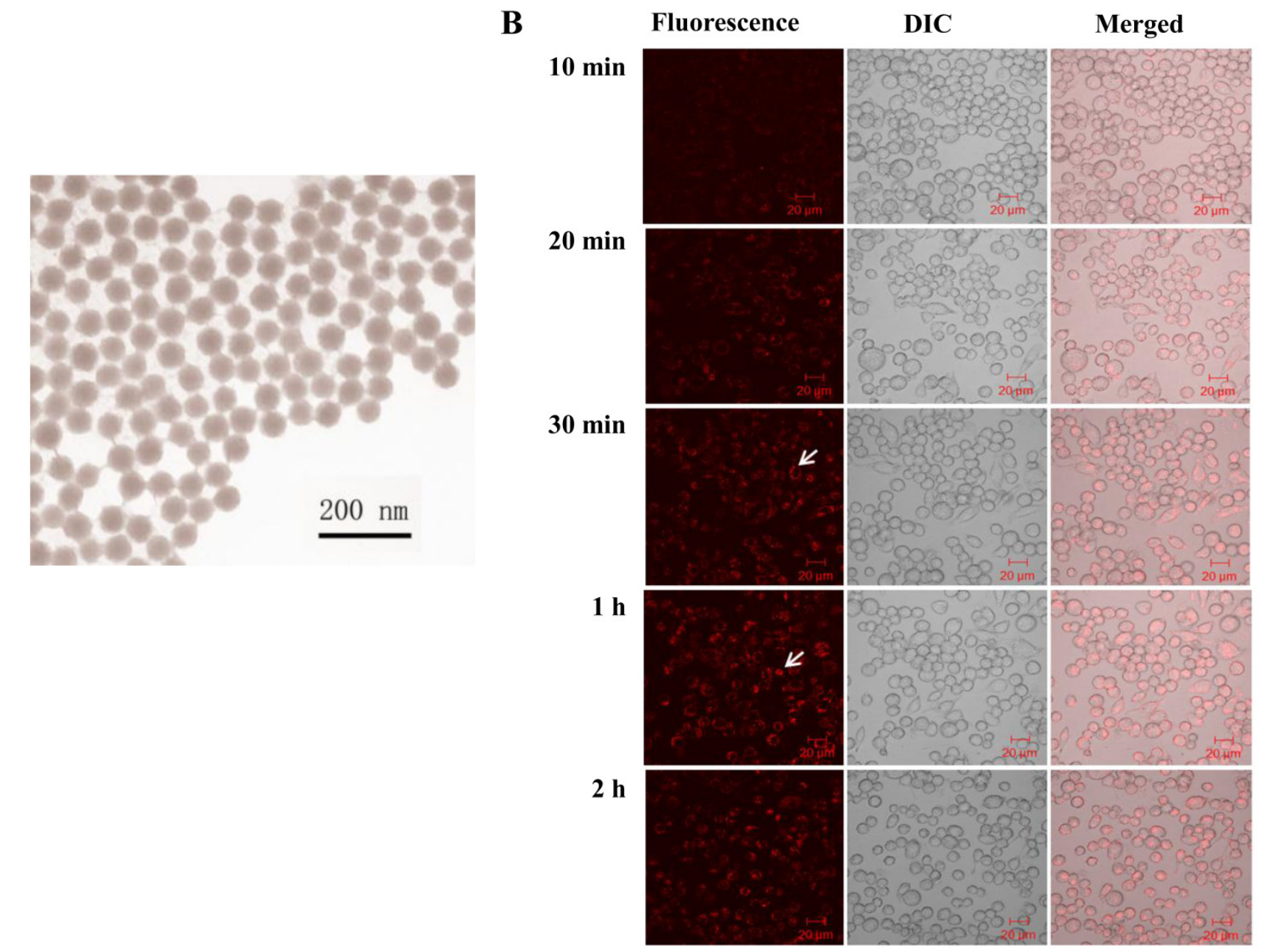

B

$10 \mathrm{~min}$

Figure I. (A) TEM image of RuBpy-doped silica NPs. The size of NPs was $50 \pm 3 \mathrm{~nm}$ in diameter. (B) The NPs induced penetration into MH-S cells. 0.2 $\mathrm{mg} / \mathrm{mL}$ RuBpy-doped NPs were used to treat the MH-S cells (arrow indicating significant penetration). Objective: $63 \mathrm{X}$; excitation wavelength: $453 \mathrm{~nm}$; and the emission filter: $580 \mathrm{~nm}$ long wavelength pass filter. The sample was placed in a chamber slide in a bath at $37^{\circ} \mathrm{C}$. The data are representative of three experiments.

The penetration of the NPs into the cells was monitored under a laser scanning confocal fluorescence microscope. MH-S cells were first incubated in a cell culture medium containing $0.2 \mathrm{mg} / \mathrm{mL}$ of RuBpy $(3.36 \mu \mathrm{M})$ doped NPs in a glass-bottomed microwell dish. In the penetration process, the fluorescence images were taken at different time periods (Figure 1B). The NPs penetrated MH-S cells quickly. The fluorescence was observed at the time period of $10 \mathrm{~min}$. The fluorescence signals in the cells significantly increased by the time of $30 \mathrm{~min}$ and reached the maximum at 1 $\mathrm{h}$, indicating that the penetration of silica NPs to MH-S cells was relatively fast. To provide sufficient time for the cells to respond to the uptake NPs, $2 \mathrm{~h}$ incubation with the NPs was also used. The fluorescence intensity showed no difference with that of the 1 $\mathrm{h}$ of treatment (Figure 1B). The NPs appeared to localize outside of the cell nuclei. Furthermore, the NPs were internalized into the cells and were confirmed by performing a $\mathrm{Z}$ series of confocal imaging after washing (data not shown). The fluorescence intensity was measured in the section of the cell center. The cells treated with the control NPs were imaged as a control. The surface-adherent particles can be easily distinguished from the internalized NPs by 3D reconstruction of the $\mathrm{Z}$ series using the Zeiss LSM software. The results confirmed that the RuBpy-doped NPs have penetrated the cells.

\section{Generation of ROS by RuBpy Molecules under Irradiation}

As a common fluorescent dye, RuBpy molecules have been well documented for their photosensitivity [50]. The mechanism of the generation of singlet oxygen by RuBpy under irradiation was illustrated in the following pathway: 


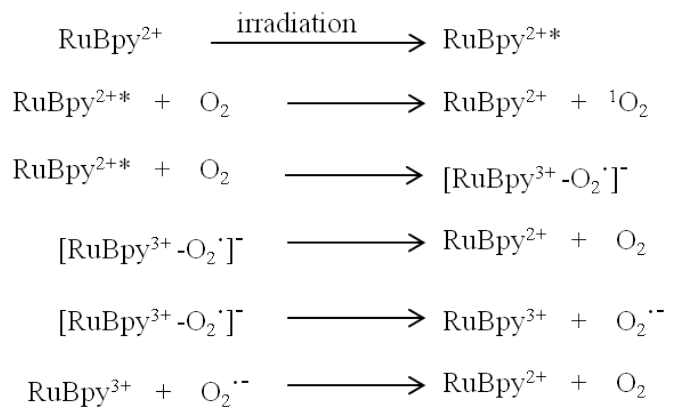

In the process of the RuBpy-induced ROS under irradiation, the RuBpy ${ }^{2+}$ is first excited by irradiation (eq.1). The excited RuBpy ${ }^{2+*}$ reacts with oxygen $\left(\mathrm{O}_{2}\right)$ and generates singlet oxygen ${ }^{1} \mathrm{O}_{2}$ (eq.2). Meanwhile, in addition to the generation of the ${ }^{1} \mathrm{O}_{2}$, some excited $\mathrm{RuBpy}^{2+}$ can return to the ground state through the reaction with oxygen and forms a complex containing free radical (eq.3). The complex can directly return to the ground state through simply dissociation into $\mathrm{RuBpy}^{2+}$ and oxygen (eq.4), or the complex forms an oxidized RuBpy and oxygen radical (eq.5). The oxidized $\mathrm{RuBpy}^{2+}$ quenches the oxygen radical and returns them to the ground state (eq.6).

It is clear that RuBpy can generate singlet oxygen. However, the phototoxicity of RuBpy molecules to living cells has not been reported. Therefore, we treated MH-S cells with a pure RuBpy molecule solution and then investigated its ability to generate ROS. A blue light $(450 \mathrm{~nm})$ was used as the irradiation source because its emission wavelength matches the excitation wavelength of RuBpy. Since previous studies strongly indicate the transmission of RuBpy ${ }^{2+}$ around $450 \mathrm{~nm}$ regions upon excitation $[35,51]$, we believe that blue light is sufficient to induce the ROS. In addition, others have also used UV light to irradiate this dye. The irradiation time to the cells was performed from $0.5 \mathrm{~h}$ to $6 \mathrm{~h}$. The generation of the singlet oxygen was detected using the NBT assay. Figure 2A showed that compared to the control cells a significant amount of ROS was generated under the irradiation when the MH-S cells were treated with RuBpy. The amount of generated ROS was dependent on the irradiation time. With $1 \mathrm{~h}$ of irradiation the level of ROS increased 1.5-fold versus the control (PBS). As the irradiation time prolonged to $6 \mathrm{~h}$, the amount of ROS was 2.3-fold higher than the control group.

We then tested the effect of RuBpy concentration on the production of ROS. As shown in Figure 2B, under the same number of cells and irradiation time period, the generated ROS was proportional to the RuBpy concentration. Two different concentrations of RuBpy solutions, $1.68 \mu \mathrm{M}$ and $3.36 \mu \mathrm{M}$, were added into the MH-S cells. The cells treated with the PBS buffer were used as a control. After $6 \mathrm{~h}$ of irradiation treatment, the ROS signals were determined using the NBT assay. The results showed that at a lower concentration of RuBpy $(1.68 \mu \mathrm{M})$ the irradiation had minimal effects on the generation of ROS, which was comparable to that without the irradiation. When the RuBpy concentration increased to $3.36 \mu \mathrm{M}$, a significant increase (more than 4-fold) of ROS was observed as analyzed with the student's $t$-test. Therefore, the ability of $\mathrm{RuBpy}^{2+}$ to generate ROS in living systems under irradiation was concentration dependent.

\section{Generation of ROS by the RuBpy-doped NPs}

To investigate the phototoxicity of RuBpy-doped silica NPs, MH-S cells were irradiated for different time periods after the NP treatment. Their ROS amounts were detected using the method mentioned above. Cells were treated with PBS buffer, control NPs, or the RuBpy-doped NPs. The pure RuBpy molecule solution was also used to treat the cells as a comparison with the RuBpy-doped NPs. The concentration of $3.36 \mu \mathrm{M}$ RuBpy molecules was chosen since this concentration could generate significant amount of ROS in the RuBpy molecule solution as determined by our initial assessment. To have a valid comparison $0.2 \mathrm{mg} / \mathrm{ml} \mathrm{RuBpy-doped} \mathrm{NPs} \mathrm{was} \mathrm{used} \mathrm{because} \mathrm{this}$ concentration of the NPs equaled to $3.36 \mu \mathrm{M}$ RuBpy. The generated ROS in these systems was measured. The result from $6 \mathrm{~h}$ irradiation was shown in Figure 2C. In the PBS buffer treated cells, the irradiation induced no notable ROS. However, the RuBpy-doped NPs induced significant amount of ROS under the irradiation and it was about 30\% less than RuBpy alone. Compared to the RuBpy dye alone, the silica matrix-coating may prevent RuBpy from interaction with oxygen, thus reducing the ROS generation. Surprisingly, the control NPs also produced detectable amount of ROS albeit much lower than the RuBpy-doped NPs. This suggests that silica material may contain some intrinsic oxidative effects albeit it is usually much lower than some other heavy metals or oxidized chemicals. A recent study showed that the gold nanorod-covered kanamycin-loaded hollow $\mathrm{SiO}_{2}$ 
nanocapsules has photothermal effects [50] and our unpublished data also indicate that the silica-gold-silica NPs provide the photothermal effect

A

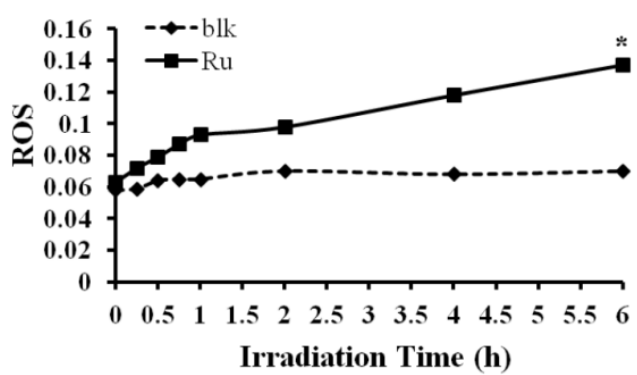

C

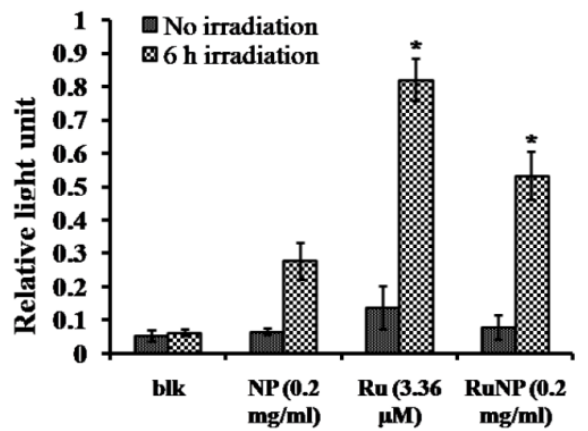

possibly due to the oxidative stress. These results indicated that the RuBpy-doped NPs can stimulate significant amounts of ROS.

B

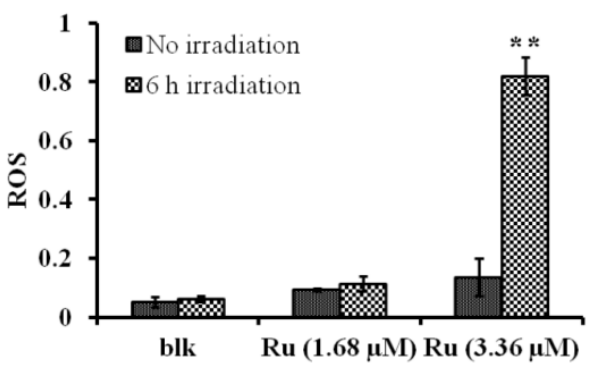

D

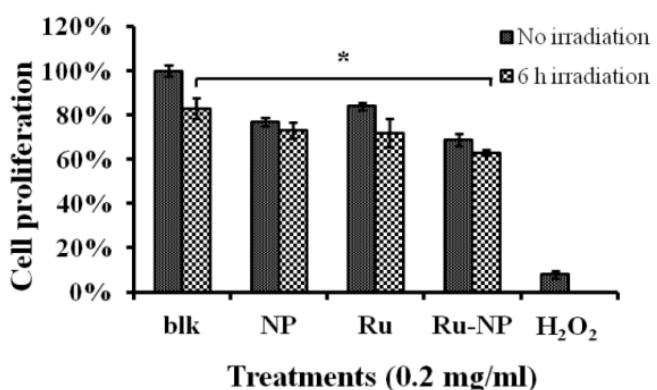

Figure 2. RuBpy induced ROS in living cells. The cells were irradiated for $6 \mathrm{~h}$. The cells treated with PBS buffer were irradiated as a control. (A) MH-S cells were treated with RuBpy for $2 \mathrm{~h}$, and irradiated for various time periods. ROS signals at different irradiation time periods were detected with the NBT assay. (B) Different concentrations of RuBpy ${ }^{2+}$ induced ROS ( $1.68 \mu \mathrm{M}=0.1 \mathrm{mg} / \mathrm{mL}, 3.36 \mu \mathrm{M}=0.2 \mathrm{mg} / \mathrm{mL}$ ) determined by $\mathrm{H}_{2}$ DCF-DA method. (C) Rubpy ${ }^{2+}$ doped NPs induced ROS in MH-S cells. $0.2 \mathrm{mg} / \mathrm{mL}$ RuBpy-doped NPs or the control NPs (same size but without doped dye) were used to treat the MH-S cells for $2 \mathrm{~h}$. Cells treated with PBS used as control. After the NP treatment, cells were subjected to $6 \mathrm{~h}$ irradiation. ROS levels were measured by NBT assay. (D) Effects of NPs, RuBpy and RuBpy-NPs on cell viability in MH-S cells as measured by MTT assay. The data are presented as means \pm SEM and are representative of three experiments (one-way ANOVA (Tukey's post hoc); $* p<0.05$; ** $p<0.01$ ).

\section{Effect of RuBpy-doped NPs on Cell Viability}

We showed that the irradiation of the cells uptaken NPs significantly increased the generation of ROS. Therefore we sought to determine the effect of the increased ROS on cell viability. First, we evaluated the cell viability rates by MTT assay, and found that NPs, RuBpy and RuBpy-NPs all caused somewhat toxicity (inhibition cell viability), but no significant differences between NPs and RuBpy-NPs were observed (Figure 2D). These results suggest that the NPs and modified NPs did not inflict significant intolerable toxic effects to living cells, suggesting that they may be safe if used in animals and clinical settings. Since MTT assay does not differentiate cell death mechanisms, we then used Vybrant assay to distinguish the difference between apoptosis and necrosis. The YO-PRO-1 dye can only permeate the cell membrane when the cell has undergone apoptosis (membrane integrity damaged). The results showed appreciative fluorescence staining indicating that the RuBpy-doped NPs induced significant apoptosis under the irradiation (Figure 3A). However, no apparent apoptosis was observed in the absence of the NPs or in the absence of irradiation. To confirm the verity of the data, we used $\mathrm{H}_{2} \mathrm{O}_{2}$ as a positive control, which is a widely-used oxidant to produce ROS. As expected, $\mathrm{H}_{2} \mathrm{O}_{2}$ induced significant apoptosis (Figure 3A). To ensure that there is no aggregate-induced effect after adding NPs into the culture medium, we observed the status of NPs and RuBpy-NPs after $1 \mathrm{~h}$ incubation with RPMI1640 medium used in this assay. Our data from SEM indicate that the size of NPs was $50 \pm 3 \mathrm{~nm}$ in diameter. Importantly, no apparent aggregates were formed in the culture medium with serum (Figure 3B), indicating that processing with NPs did not induce extra physicochemical effects to damage cells. Besides the Vybrant assay, a flow cytometry assay was also applied to detect apoptosis rates (Figure 4A and $\mathrm{B}, \mathrm{B}$ representing the scattered graph of the RuBpy-NPs with or without irradiation). Statistical analysis showed that RuBpy-doped NP treatment without irradiation induced about $8 \%$ apoptotic cells. Combination of the RuBpy-doped NP treatment with 
$6 \mathrm{~h}$ irradiation induced more than $20 \%$ apoptotic cells. However, other treatments such as RuBpy alone or pure NPs, failed to induce significant apoptosis in the presence or absence of irradiation (Figure 4A). Since the function of macrophages is to phagocytize and clear invading organisms or macromolecules, significant amounts of NPs can be toxic to the cells. The data shown here suggest that the RuBpy-doped silica NPs' treatment was more toxic than the silica NPs without RuBpy, which is consistent with the results of ROS generation. Meanwhile, these results indicate that the RuBpy dye molecules induced significant apoptosis under irradiation. Interestingly, although we have demonstrated that the cells treated with RuBpy dye produced more ROS than the cells treated with the
RuBpy-doped silica NPs, the RuBpy-doped silica NPs caused more significant apoptosis than the dye molecules alone. The possible explanation of this phenomenon could be traced in Figure 2C, where the pure silica NPs induced a detectable amount of ROS. In addition, the NPs facilitated retained the dye molecules inside of the cells compared with dye alone. Furthermore, the doping procedures may already have changed the physicochemical properties of the dye-doped NPs. In this case, under irradiation, the RuBpy-doped silica NPs caused greater apoptosis in MH-S cells than the dye alone or NPs alone, indicating its potential value in clinical therapeutic application.

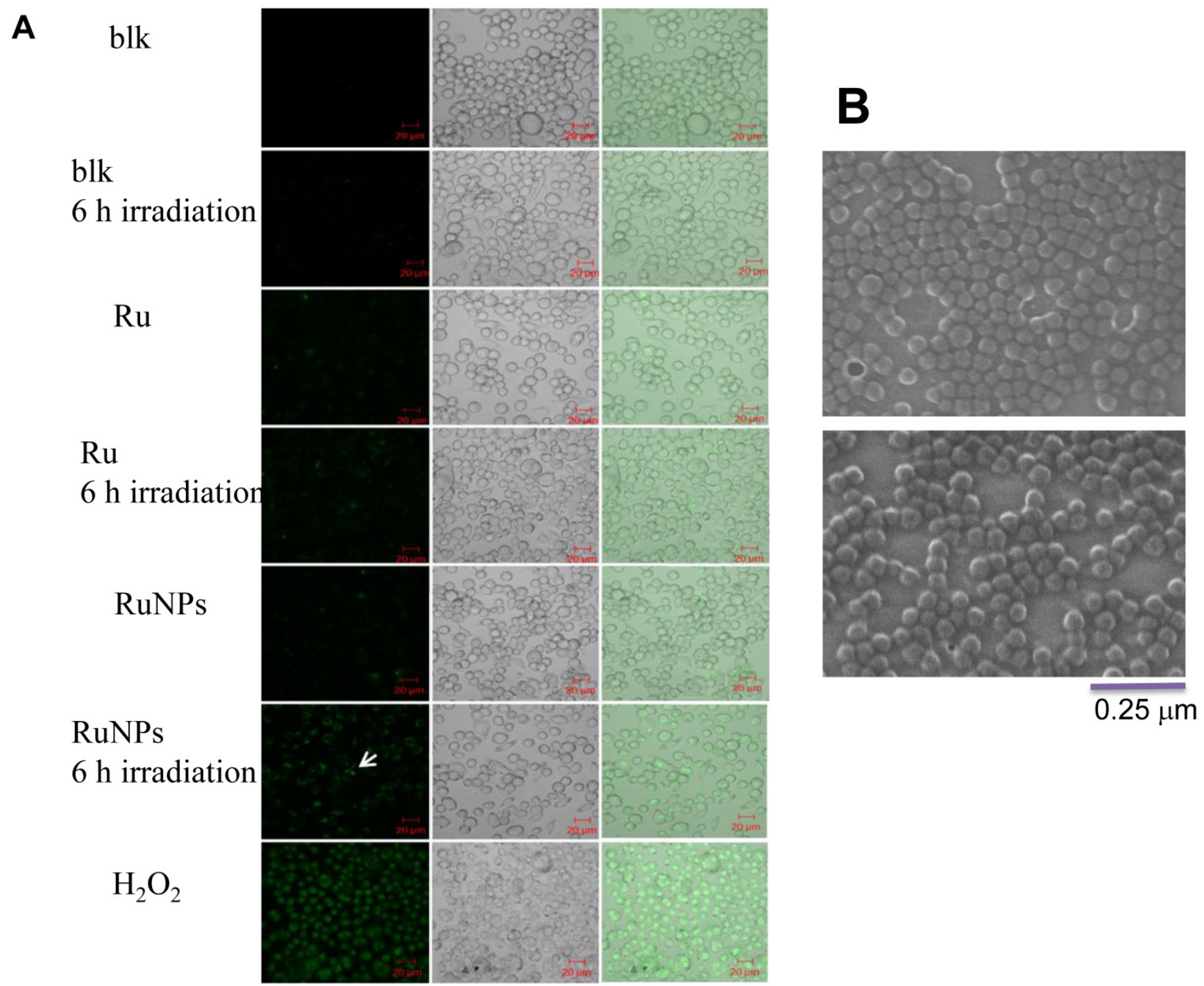

Figure 3. Apoptosis of MH-S cells induced by RuBpy-doped NPs determined by Vybrant assay. (A) $0.2 \mathrm{mg} / \mathrm{mL}$ RuBpy-doped NPs were added to the cells. Cells treated with PBS and $\mathrm{H}_{2} \mathrm{O}_{2}$ used as a negative and a positive control. After $6 \mathrm{~h}$ irradiation, the YO-PO-I dye showed the apoptosis cells (indicated with an arrow). The fluorescence signals were visualized by a confocal microscope. Objective $63 \mathrm{X}$, excitation wavelength $488 \mathrm{~nm}$. (B) No aggregates were formed after I h incubation in RPMII 640 culture medium containing $10 \%$ serum assessed by SEM. The size of NPs was $50 \pm 3 \mathrm{~nm}$ in diameter. 


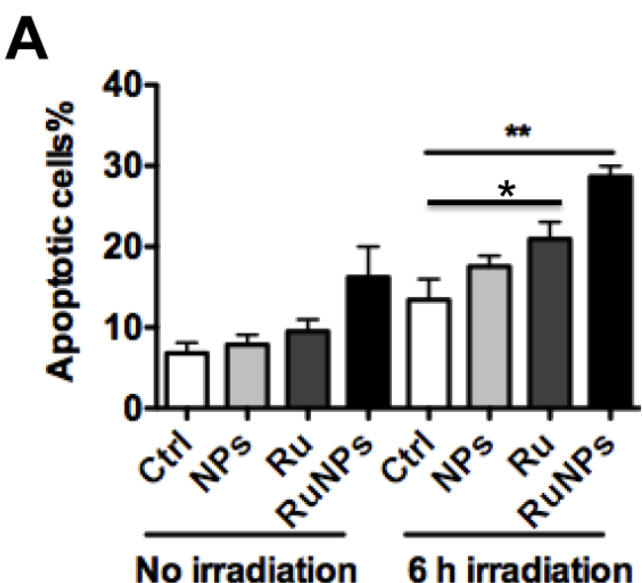

B
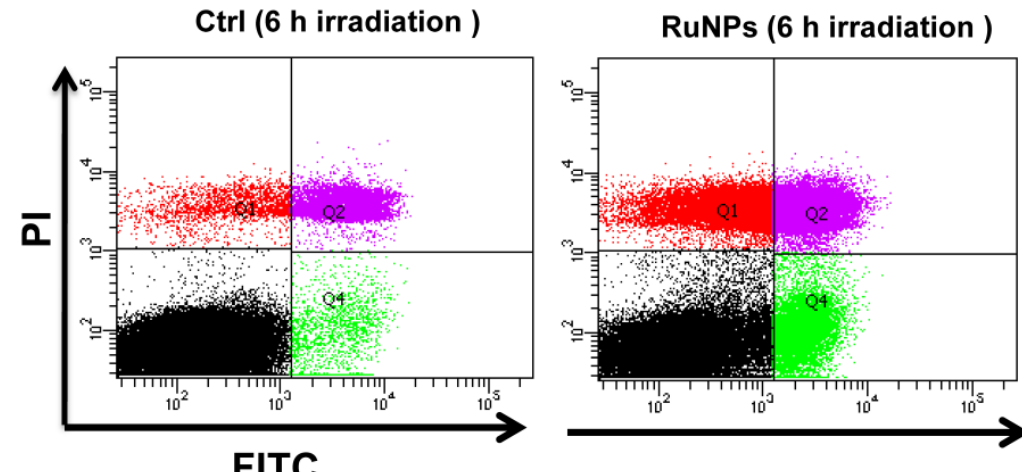

FITC

Figure 4. Quantitative evaluation of apoptosis by a flow cytometry assay. $0.2 \mathrm{mg} / \mathrm{mL}$ RuBpy-doped NPs were added to the cells. MH-S cells were treated with PBS (blk), control NPs (NP), RuBpy-dye (Ru) or the Rubpy-doped NPs (RuNPs) for $2 \mathrm{~h}$. Then cells were subjected to $6 \mathrm{~h}$ irradiation or incubated in the dark as controls. Apoptosis of Annexin V-FITC-stained cells was assayed by flow cytometry. (A) Quantitative measurement of apoptosis with the above samples. (B) Scattered distribution graph of apoptotic staining of the RuBpy-NPs with or without irradiation. The data of apoptotic percentage of treated-cells vs. the control are representative of two experiments. The data are presented as means \pm SDEV and are representative of two experiments (one-way ANOVA (Tukey's post hoc); ${ }^{*} p<0.05 ; * *<0.01$ ).

\section{DNA Damage Induced by the RuBpy-doped NPs under Irradiation}

To understand the mechanism of the RuBpy-doped silica NPs-induced apoptosis, we detected the impact of the RuBpy-doped NPs on DNA integrity using a comet assay. $\mathrm{H}_{2} \mathrm{O}_{2}$ was used to treat the cells as a positive control. The results showed that under the irradiation, the comet tails increased in the RuBpy-doped NPs treated cells (Figure 5A). Similarly, under the irradiation, the comet tails were increased after the treatment using the pure RuBpy solution. However, with the same irradiation time, there was no comet tail presented in the PBS buffer treated cells or the control NPs treaded cells. The length of the comet tail was shown in Figure 5B. RuBpy-doped NPs can induce DNA damage under irradiation, consistent with the increased ROS with the same treatments (Figure 2). Moreover, we found that with the same amount of RuBpy, the RuBpy-doped NPs are more genotoxic to DNA than the RuBpy dye. This result was consistent with the apoptosis induction from the Vybrant assay and flow cytometry assay.

\section{In vivo Study of the Toxicity of the RuBpy-doped NPs}

Although a recent study demonstrated that the shape of silica NPs minimally affects in vivo toxicity [52], to our knowledge the RuBpy-doped NPs have not been evaluated for their toxicity in animals. To investigate the physiological relevance, we examined the RuBpy-doped silica NPs-induced toxicity in mice. Based on the above results, apparently, the ROS induced by the RuBpy-doped silica NPs was a primary contributing factor of phototoxicity to living cells. As the MPO is a recognized influx for oxidation in tissue, we instilled the RuBpy-doped NPs or the PBS control and determined MPO activity in the lung and other organs (the kidney and liver) in the mice. As expected, the significantly increased MPO activity was observed in the lung in the RuBpy-doped NP group vs. the PBS control group (Figure 6A, ${ }^{*} p<0.05$ ). However, there were no obvious differences in the kidney and liver tissues after the NP instillation (Figure 6B, C). To further understand this toxic mechanism, we determined lipid peroxidation as it is a critical cell membrane injury indicator. As shown in Figure 6D, lipid peroxidation levels were significantly increased in the RubBpy-doped NP-treated mice compared to the PBS control mice $\left({ }^{*} p<0.05\right)$. Similar to the MPO influx, lipid peroxidation levels in the kidney and liver tissues had no significant changes (Figure 6E, F). Apparently, the NPs also induced significant lung lipid peroxidation than other organs, which may be a chief contributing factor towards the NPs-induced toxicity. Importantly, different amounts of MPO and lipid peroxidation in different organs may indicate that the NP toxicity is still limited in the organs which received the RuBpy-doped NPs rather than dissemination into distant organs.

\section{RuBpy-doped NPs Altered Cytokine Secretion and Signaling Proteins in Mouse Lungs}

To illustrate the mechanism and physiological relevance of RuBpy-doped NP, we intranasally instilled the NPs into C57BL/6J mice and assessed expression of critical signaling proteins in lung tissues by Western blotting (Figure 7A, B). We found that the expression levels of High mobility group box 1 (HMGB1, a danger indicator cytokine) and Nuclear 
factor (erythroid-derived 2)-like 2 (Nrf2, an oxidative responder) decreased significantly in the NP-treated mice compared to PBS-treated mice, while the levels of Caspase-1 and TNFa (innate immunity or inflammation) as well as IL-4 (Th2 cytokine) were not altered. However, HMGB1 in the liver of the NP-treated mice somewhat increased. This indicates that various organs may have distinct responses against RuBpy-doped NPs in mice. Importantly, phosphorylation of transcription factor (NFKB), ERK1/2 and Akt increased in the NP-treated mice compared to PBS-treated mice, although the protein levels of Akt and NFKB were not altered (Figure 7A, B). Although the detailed mechanism needs further research, these analyses have demonstrated that danger signaling and oxidative regulators were down-regulated in the lung, whereas signals for cell proliferation and cytoskeletal activity were activated. Interestingly, despite somewhat increased phosphorylation of NFKB and ERK1/2, at the dose of application RuBpy-doped NPs only caused mild cytokine-mediated inflammatory responses and even down-regulated certain inflammatory cytokines such as HMGB1. It is perhaps counterintuitive that activation of $\mathrm{NF \kappa B}$ could not cause significant cytokine responses. The underlying mechanism is unclear; however, this may be because the NPs have special characteristics. The additional reason may be that we have not exposed the mice received the RuBpy-doped NPs with light irradiation in vivo. Nevertheless, the increase in NFKB phosphorylation is not quite robust. Furthermore, no mortality was noticed during the one week study. Since inflammatory responses were not as dramatic as some other NPs (i.e., quantum dots) shown previously [53], we conclude that RuBpy-doped NPs may not possess significant intrinsic toxicity to mammals.

A
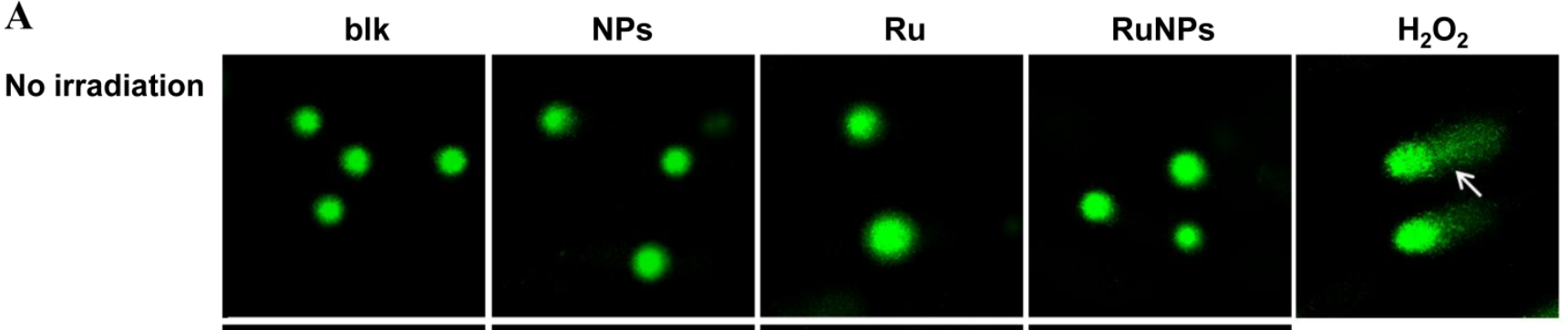

6h irradiation
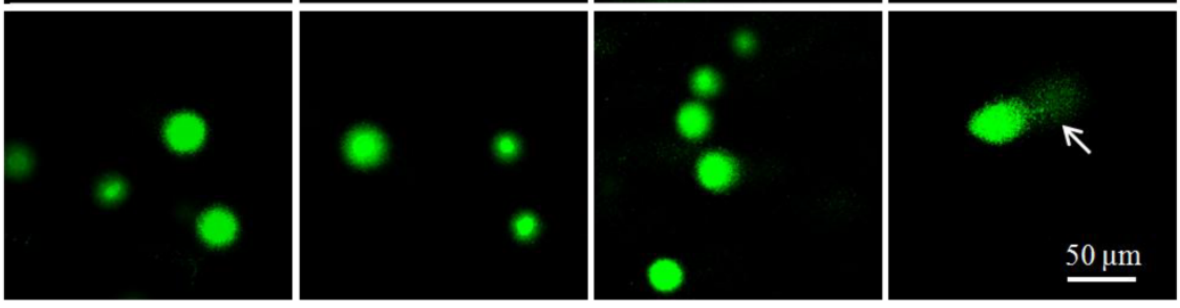

B

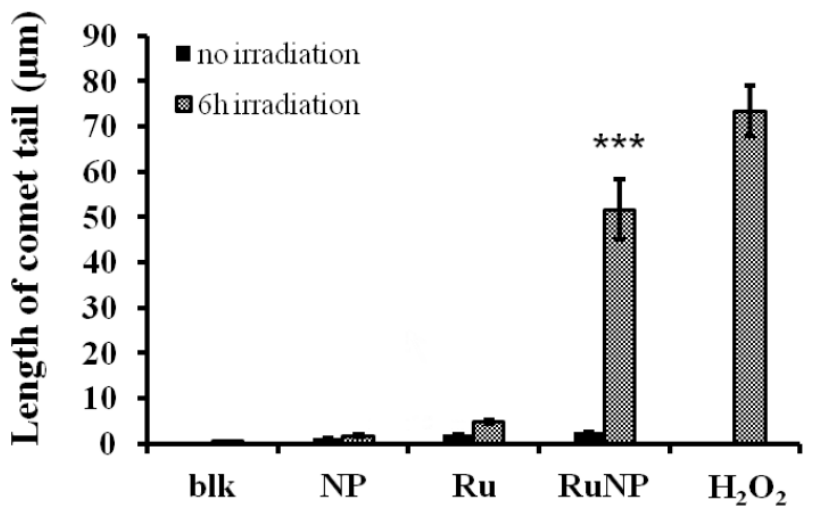

Figure 5 Detection of DNA single strand breaks by a comet assay. (A) MH-S cells were treated with PBS (blk), control NPs (NP), RuBpy-dye (Ru) or the Rubpy-doped NPs (Ru-NPs) for $2 \mathrm{~h}$. For each treatment, one group of cells was subjected to $6 \mathrm{~h}$ irradiation and the other was incubated in the dark. The DNAs were evaluated by a comet assay and stained with SYBR Green. The DNA integrity was imaged with confocal microscope (arrow indicating significant DNA comet tail). (B) The comet tail length was defined as the distance between the leading edge of the nucleus and the end of the tail. The data are representative of three experiments. 

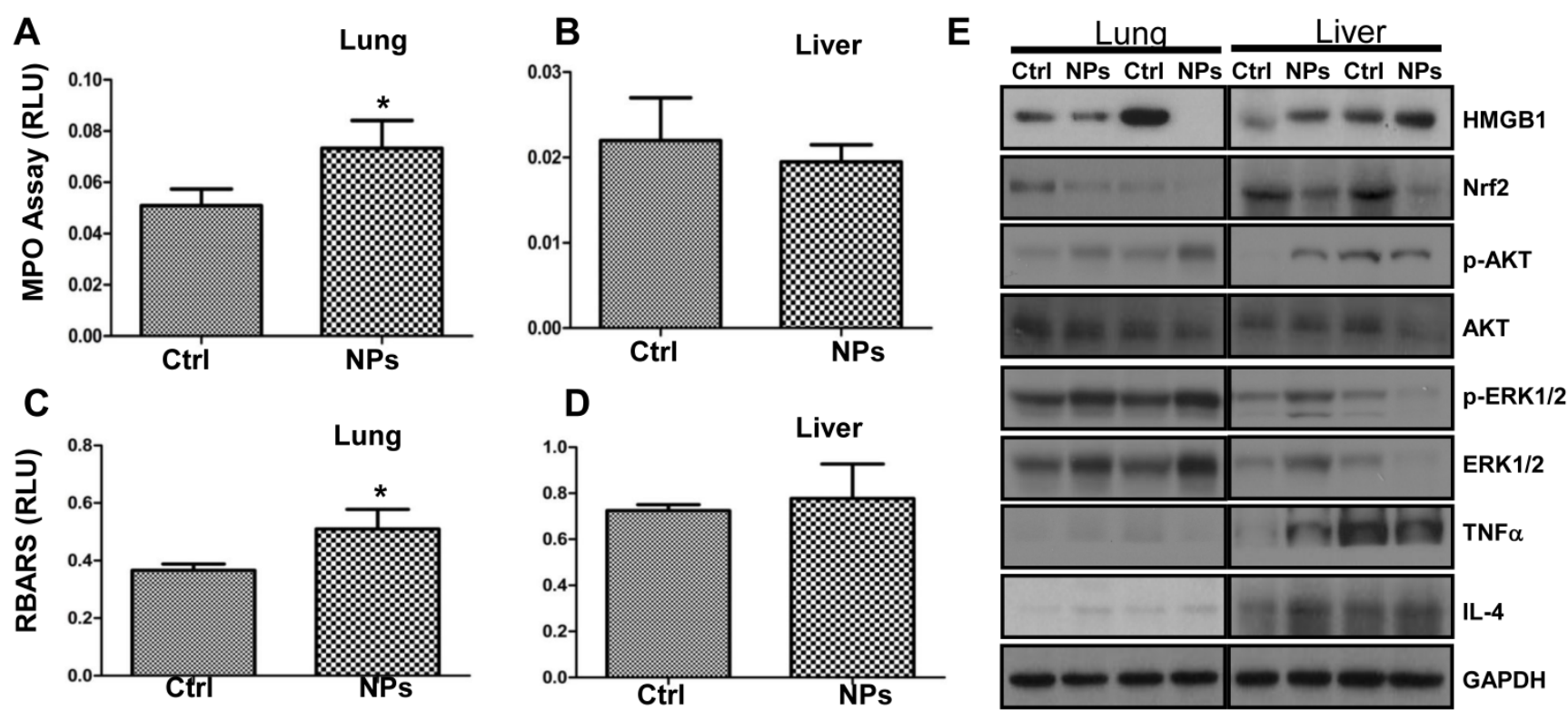

Figure 6. RuBpy-doped NPs showed increased lung oxidation in vivo. (A) Increased MPO activity in lung but not in the kidney and liver in RuBpy-doped NPs treated mice $(n=5)$. (B) Increased levels of lipid peroxidation were observed in the lung, but not in the kidney and liver tissues of RuBpy-doped NPs treated mice as assessed by the thiobarbituric acid-reactive substance assay. The data are presented as means \pm SEM and are representative of three experiments (one-way ANOVA (Tukey's post hoc); * $p<0.05$ ). RLU, relative luciferase units.

A

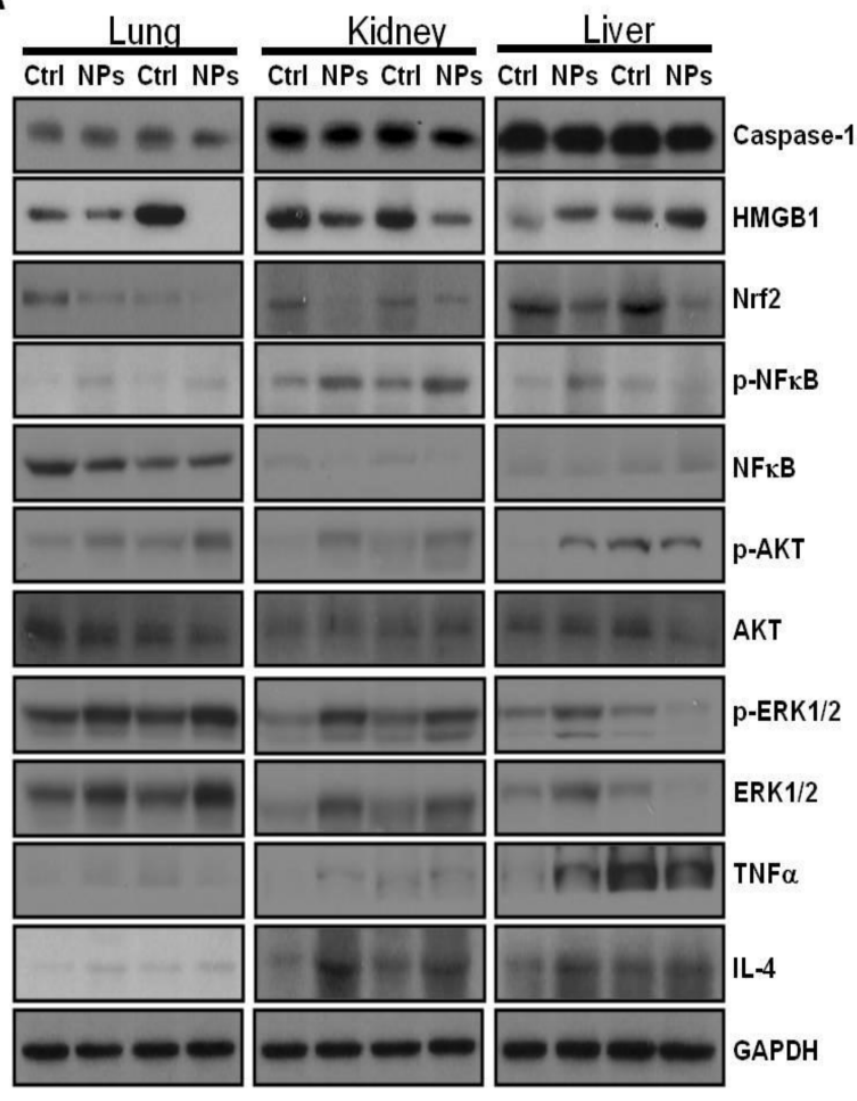

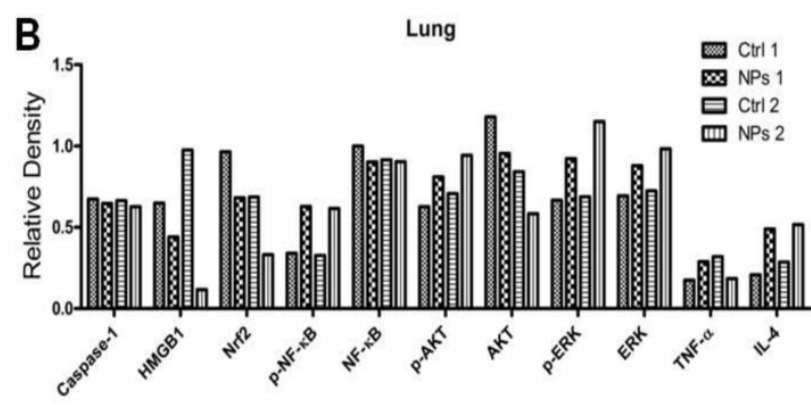
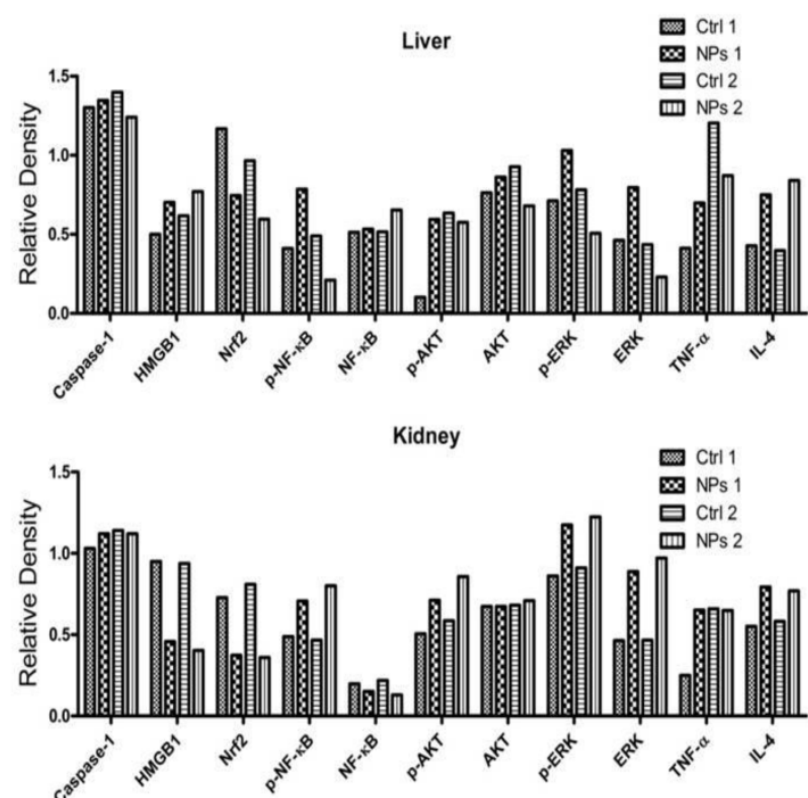

Figure 7. RuBpy-doped NPs altered the expression of cytokines and signaling proteins in mouse lungs $(n=5)$. Expression of the indicated molecules was determined by western blotting (A) and quantified using densitometry after normalization with loading controls (B). GAPDH was probed for loading controls. Gel samples are shown in duplicate and are representative of three experiments. The data are presented as means \pm SDEV and are representative of three experiments (one-way ANOVA (Tukey's post hoc); * $p<0.05$ ). 


\section{Irradiation intensified RuBpy-doped NP-mediated Cell Signaling Activation in Mice}

Limited studies have investigated phototherapeutic roles of the blue light in animals [54,55], with one notable example showing that LED can penetrate to the tissue of young rats and resulting in significant apoptosis in the intestine [56]. To further determine the thermotherapeutic potential of the Dye-doped NPs, we evaluated whether irradiation can alter physicochemical, inflammatory and toxic properties of the NPs in mice. We found that the lung showed high level expression of Nrf2 and TNF- $\alpha$ (Figure 8 and Additional file 1: Supplementary Figure 1A, B), while the liver exhibited high levels of ERK and IL-4 as well as increased phosphor-NF- $\mathrm{KB}$ (maybe the mechanism of causing more significant inflammation and thermotherapeutic effects) by RuBpy alone and Dye-doped silica NPs after $6 \mathrm{~h}$ irradiation of mice (Figure 8 and Additional file 1: Supplementary Figure 2A, B). Strikingly, we also found that in the kidney both RuBpy alone and silica NPs induced systemic signaling activation including Caspase1, HMGB1, Nrf2, phosphor-NF-kB, Akt, phosphor-Akt, phosphor-ERK1/2, TNF- $\alpha$, and IL-4, compared to the liver and lung where showed highly selective signaling patterns (Figure 8 and Additional file 1: Supplementary Figure 3A, B).

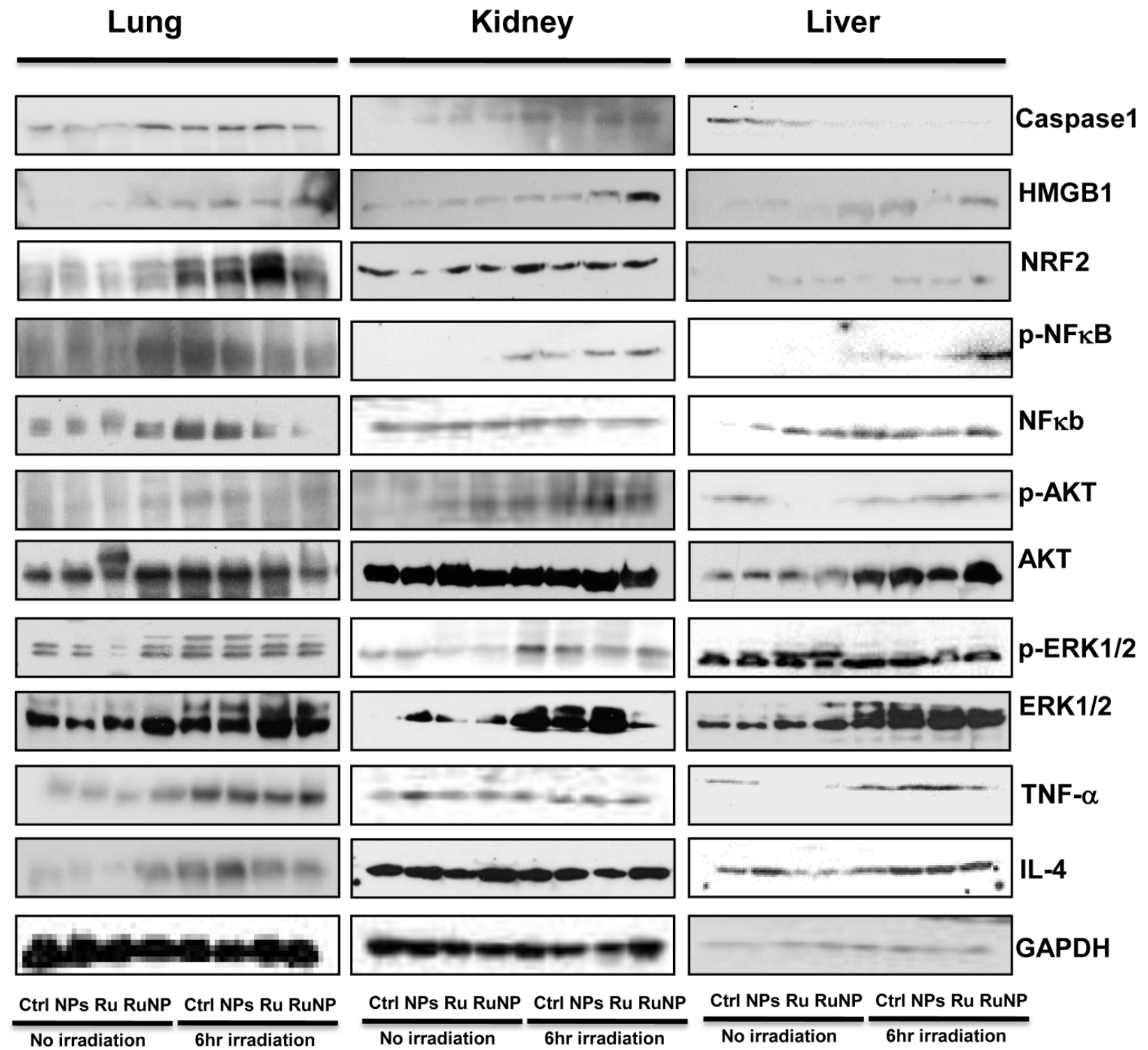

Figure 8. Irradiation further increased RuBpy-doped NP-mediated the expression of cytokines and signaling proteins in mice ( $n=5$ ). Expression and phosphorylation of the indicated signaling proteins in the lungs, liver and kidneys were determined by western blotting. GAPDH was probed for loading controls. Different organ samples were homogenized and resolved in a protein gel. The data are representative of two experiments. The data are presented as means \pm SDEV and are representative of three experiments (one-way ANOVA (Tukey's post hoc); $*<<0.05$ ). 
Interestingly, these markers have been more pronounced increased in NPs or Rubpy alone controls but less so in RuBpy-NPs group in the kidney, indicating that RuBpy-NPs may not be strong inflammatory inducers compared to RuBpy or NPs alone. This characteristic is important for clinical therapy using the RuBpy-NPs. Moreover, we noted that the lung expressed extraordinarily high levels of HMGB-1 (about 40-fold), while the liver expressed Akt (65-fold) and TNF- $\alpha$ (20 fold) (Figure 8 and Additional file 1: Supplementary Figure 4). Therefore our findings indicate that silica NPs may mediate a complex profile in inducing cellular activity and inflammatory responses in animals. It is evident that many critical signaling proteins are differentially regulated by NPs treatment in the presence of irradiation. Nevertheless, considering the activation of HMGB1 by NPs without irradiation, and its broad activation in all organs tested (lung, liver, and kidney), we propose that HMGB1 is a critical indicator of systemic physiological stress signaling in response to NPs-induced toxicity and inflammation. Our studies are the first to identify the important role of HMGB1 in signaling NPs-mediated oxidative information. Although Nrf2 was increased both in the lung and kidney but its expression in the liver is not so high. Our study also clearly indicates that Nrf2 is associated with NPs inflammation in mice, consistent with a previous study discussing silica NP toxicity despite being only performed in cell culture [53].

\section{Discussion}

In the current study, we synthesized novel RuBpy-doped silica NPs and evaluated their physicochemical, inflammatory and toxic features towards living cells and entire animals. Using oxidation and toxicity analysis with several approaches, we demonstrate that the RuBpy-doped silica NPs could induce significant amount of ROS and toxicity in MH-S cells under $6 \mathrm{~h}$ irradiation when the RuBpy concentration is higher than $3.36 \mu \mathrm{M}(0.2 \mathrm{mg} / \mathrm{mL} \mathrm{NPs})$. As the irradiation over $30 \mathrm{~min}$, the induced ROS was detectable. The period of $30 \mathrm{~min}$ is relatively long time for bioimaging and bioanalysis where the irradiation time may be much shorter. However, this result may provide a safety consideration for the situation where a longer period of irradiation needs to be employed. Control NPs may also induce ROS, but it did not cause significant DNA damage or apoptosis. Our result is consistent with other reports [33, 57-59]. An interesting result is that the RuBpy-doped NPs may induce less ROS than RuBpy dye alone due to the protective role of silica matrix. However, the addition of nanomatrix increased cellular response required for therapeutic applications as the RuBpy-doped silica NPs are more toxic for causing apoptosis than the dye molecules alone or the control NPs. Thus, RuBpy-doped silica NPs may cause the phototoxicity if the irradiation time is longer than $30 \mathrm{~min}$.

Previously, there were limited reports investigating phototherapeutic effects of a novel blue light device in animals and humans with improved efficacy compared to conventional methods [54-56]. For instance, Tanaka et al., showed that the blue light at 450 $\mathrm{nm}$ can induce significant apoptosis in the intestine, suggesting that blue light generated with LED can penetrate to the tissue of young rats [56]. The authors also speculated that blue light phototherapy for animals may not cause perforation if the wavelength is controlled around a narrow range between 450-458 $\mathrm{nm}$. Indeed, blue light is considered as lower end of visible light which is proven to have penetration to tissue approximately $3 \mathrm{~mm}$ depth [60]. Furthermore, phototherapy by blue light may exert its effect via ROS, including nitric oxide (NO), which may be the mechanism for impacting deep tissue [61-63].

To our knowledge, no previous studies have investigated the physiological influence of RuBpy-doped silica NPs in animals. Thus, we performed in vivo studies to measure the nature of the RuBpy-doped NPs using a commonly used mouse model with the C57BL/6J strain. We found airway delivery of RuBpy-doped NPs only induced somewhat slight lung injury with increased MPO activity (a sign of increased neutrophil accumulation) and lipid peroxidation while no such changes occurred in the kidney or liver. This is crucial information as the data indicate for the first time that the RuBpy-doped NPs may have no or limited penetration to other organs if not injected through intravenous routes. As we have not noticed mortality or strong inflammatory responses as shown with other NPs for a period up to 2 weeks [52], we speculate that the concentrations of RuBpy-doped NPs in our studies may be tolerated in mice. These findings suggest that RuBpy-doped NPs may not possess too strong intrinsic toxicity to mice or other mammals. It is somewhat difficult in explaining why activation of NFKB (not significantly in the lung) did not cause significant cytokine responses, but it did activate proliferative cell signaling, such as Akt and ERK1/2 which was previously shown to be inducible by the NFKB pathway in different cellular models [41, $43,57,58]$. This may be explained as these NPs may have special characteristics with low intrinsic toxicity to mice tested. Moreover, the activation of NF- $\mathrm{\kappa B}$ is more significant in the kidney and liver than the lung. Nevertheless, the increase in NFKB phosphorylation is 
not as dramatic as shown in different oxidants associated conditions [57-59].

Because of the activation of HMGB1 by NPs with or without irradiation, and its universal activation in all organs tested (lung, liver, and kidney), we speculate that HMGB1 may be a potential biomarker of systemic physiological stress response to silica NPs-administration. Our studies are the first to identify the important role of HMGB1 as a danger or alarming signal for silica NPs. In addition, due to its increase both in the lung and kidney, Nrf2 may be another potential indicator for silica NP-mediated toxicity to be revealed in animal studies. Strikingly, we also found that in the kidney both RuBpy alone and silica NPs induced a broad spectrum of activation of cellular signaling proteins including Caspase1, HMGB1, Nrf2, phosphor-NF-kB, Akt, phosphor-Akt, phosphor-ERK1/2, TNF- $\alpha$, and IL-4, compared to the liver and lung, which showed highly selective signaling patterns. Overall, our studies provide important observations regarding the silica NPs and RuBpy-NPs toxicity and inflammatory induction features.

In conclusion, we have synthesized RuBpy-doped NPs and tested their toxicity features in vitro and in vivo. There was somewhat light cytotoxicity observed under irradiation by causing cell death and DNA damage, which may be exploited for therapeutic application. However, the extent of the toxicity and inflammatory responses is generally tolerable both in vitro and in vivo. We also discovered some critical biomarkers (e.g., HMGB1 and Nfr2) for silica NPs stress and toxicity and demonstrated differentially regulated stress responders in various organs. Although long-term toxicity and detailed mechanisms of these NPs in animals require additional characterization, for the first time our current study provides important information for further evaluating the safety and as guides for use in biological and biomedical systems.

\section{Supplementary Material}

Additional File 1:

Supplementary Figures 1-4.

http://www.thno.org/v04p0445s1.pdf

\section{Abbreviations}

DMSO: dimethyl sulfoxide; EDTA: ethylenediaminetetraacetic acid; $\mathrm{H}_{2} \mathrm{O}_{2}$ : hydrogen peroxide; LED: light emitting diode; MPO: myeloperoxidase; MTT: 3-(4,5-dimethylthiazol-2-yl)-2,5-diphenyltetrazolium bromide; NBT: nitroblue tetrazolium; NPs: NPs; PBS: phosphate buffered saline; QDs: quantum dots; RLU: relative luciferase units; ROS: reactive oxygen species; RuBpy: Tris(2,2'-bipyridyl) ruthenium(II) chloride;
SDS: sodium dodecyl sulfate; TEM: transmission electron microscope; TEOS: tetraethylorthosilicate.

\section{Acknowledgement}

This work was supported by the National Science Foundation Grants CHE 0911472 and CHE 0947043 to J.X.Z. This work was also supported by a TARTRIC grant W81XWH-11-2-0163 to J.X.Z. and M.W. This work was also supported by the Flight Attendant Medical Research Institute (FAMRI, Grant \#103007), National Institute of Health AI101973-01, and AI097532-01A1 to M.W.

\section{Competing Interests}

The authors declare that they have no competing financial interests.

\section{References}

1. Lee JH, Wang Z, Liu J, et al. Highly sensitive and selective colorimetric sensors for uranyl (UO2(2+)): development and comparison of labeled and label-free DNAzyme-gold nanoparticle systems. J Am Chem Soc. 2008; 130: 14217-26.

2. Leptihn S, Har JY, Chen J, et al. Single molecule resolution of the antimicrobial action of quantum dot-labeled sushi peptide on live bacteria. BMC Biol. 2009; $7: 22$.

3. Chan WC, Nie S. Quantum dot bioconjugates for ultrasensitive nonisotopic detection. Science. 1998; 281: 2016-8.

4. Medintz IL, Trammell SA, Mattoussi H, et al. Reversible modulation of quantum dot photoluminescence using a protein- bound photochromic fluorescence resonance energy transfer acceptor. J Am Chem Soc. 2004; 126: 30-1.

5. Park EJ, Brasuel M, Behrend C, et al. Ratiometric optical PEBBLE nanosensors for real-time magnesium ion concentrations inside viable cells. Anal Chem. 2003; 75: 3784-91.

6. Santra S, Zhang P, Wang K, et al. Conjugation of biomolecules with luminophore-doped silica NPs for photostable biomarkers. Anal Chem. 2001; 73: 4988-93.

7. Zhao X, Bagwe RP, Tan W. Ultrasensitive DNA detection using highly fluorescent bioconjugated NPs. J Am Chem Soc. 2004; 125: 11474-5.

8. Sharma P, Brown S, Walter G, et al. NPs for bioimaging. Adv Colloid Interface Sci. 2006; 123-126: 471-85.

9. Lian $\mathrm{W}$, Litherland SA, Badrane $\mathrm{H}$, et al. Ultrasensitive detection of biomolecules with fluorescent dye-doped NPs. Anal Biochem. 2004; 334: 135-44.

10. Wu H, Huo Q, Varnum S, et al. Dye-doped silica nanoparticle labels/protein microarray for detection of protein biomarkers. Analyst. 2008; 133: 1550-5.

11. Yong KT, Hu R, Roy I, et al. Tumor targeting and imaging in live animals with functionalized semiconductor quantum rods. ACS Appl Mater Interfaces. 2009; 1 : 710-9.

12. Pi QM, Zhang WJ, Zhou GD, et al. Degradation or excretion of quantum dots in mouse embryonic stem cells. BMC Biotechnol. 2010; 10: 36.

13. Tseng CL, Shih IL, Stobinski L, et al. Gadolinium hexanedione NPs for stem cell labeling and tracking via magnetic resonance imaging. Biomaterials. 2010; 31: 5427-35.

14. Hoshino A, Fujioka K, Oku T, et al. Physicochemical properties and cellular toxicity of nanocrystal quantum dots depend on their suiface modification. Nano Lett. 2004; 4: 2163-9.

15. Kirchner C, Liedl T, Kudera S, et al. Cytotoxicity of colloidal CdSe and CdSe/ZnS NPs. Nano Lett. 2005; 5: 331-8.

16. Shiohara A, Hoshino A, Hanaki K, et al. On the cyto-toxicity caused by quantum dots. Microbiol Immunol. 2004; 48: 669-75.

17. Derfus A, Chan WCW, Bhatia SN. Probing the cytotoxicity of semiconductor quantum dots. Nano Lett. 2004; 4: 11-8.

18. Lovric J, Bazzi HS, Cuie Y, et al. Differences in subcellular distribution and toxicity of green and red emitting CdTe quantum dots. J Mol Med (Berl). 2005; 83: 377-85.

19. Kumar CSSR. Nanostructured Oxides. Weinheim: Wiley-VCH; 2009.

20. Thomassen LC, Aerts A, Rabolli V, et al. Synthesis and characterization of stable monodisperse silica nanoparticle sols for in vitro cytotoxicity testing. Langmuir. 2010; 26: 328-35.

21. Oberdorster G, Oberdorster E, Oberdorster J. Nanotoxicology: an emerging discipline evolving from studies of ultrafine particles. Environ Health Perspect. 2005; 113: 823-39.

22. Di Pasqua AJ, Sharma KK, Shi YL, et al. Cytotoxicity of mesoporous silica nanomaterials. J Inorg Biochem. 2008; 102: 1416-23.

23. Nel A, Xia T, Madler L, et al. Toxic potential of materials at the nanolevel. Science. 2006; 311: 622-7. 
24. Baroli B, Ennas MG, Loffredo $\mathrm{F}$, et al. Penetration of metallic NPs in human full-thickness skin. J Invest Dermatol. 2007; 127: 1701-12.

25. Hagens WI, Oomen AG, de Jong WH, et al. What do we (need to) know about the kinetic properties of NPs in the body? Regul Toxicol Pharmacol. 2007; 49: 217-29.

26. Chang JS, Chang KL, Hwang DF, et al. In vitro cytotoxicitiy of silica NPs at high concentrations strongly depends on the metabolic activity type of the cell line. Environ Sci Technol. 2007; 41: 2064-8.

27. Jin $Y$, Kannan S, Wu M, et al. Toxicity of luminescent silica NPs to living cells. Chem Res Toxicol. 2007; 20: 1126-33.

28. Lewinski N, Colvin V, Drezek R. Cytotoxicity of NPs. Small. 2008; 4: 26-49.

29. Knaapen AM, Borm PJ, Albrecht $\mathrm{C}$, et al. Inhaled particles and lung cancer. Part A: Mechanisms. Int J Cancer. 2004; 109: 799-809.

30. Nel A. Atmosphere. Air pollution-related illness: effects of particles. Science. 2005; 308: 804-6.

31. Johnston CJ, Driscoll KE, Finkelstein JN, et al. Pulmonary chemokine and mutagenic responses in rats after subchronic inhalation of amorphous and crystalline silica. Toxicol Sci. 2000; 56: 405-13.

32. Nishimori $\mathrm{H}$, Kondoh $\mathrm{M}$, Isoda $\mathrm{K}$, et al. Influence of $70 \mathrm{~nm}$ silica particles in mice with cisplatin or paraquat-induced toxicity. Pharmazie. 2009; 64: 395-7.

33. Zhao X, Hilliard LR, Wang K, et al. In Encyclopedia of Nanoscience And Nanotechnology; Nalwa, H. S., Ed. American Scientific Publishers. 2004; :255.

34. Yao G, Wang L, Wu Y, et al. FloDots: luminescent NPs. Anal Bioanal Chem. 2006; 385: 518-24.

35. Zhang X, Rodgers MAJ. Energy and Electron Transfer Reactions of the MLCT state of Ruthenium Tris(bipyridyl) with Molecular Oxygen: A Laser Flash Photolysis Study. J Phys Chem. 1995; 99: 12797-803.

36. Kumar R, Roy I, Ohulchanskky TY, et al. In vivo biodistribution and clearance stuies using multimodal organically modified silica NPs. ACS Nano. 2010; 4: 699-708.

37. Zhao X, Bagwe RP, Tan W. Development of organic-dye-doped silica NPs in a reverse microemulsion. Adv Mater. 2004; 16: 173-6.

38. Bagwe RP, Yang C, Hilliard LR, et al. Optimization of dye-doped silica NPs prepared using a reverse microemulsion method. Langmuir. 2004; 20: 8336-42.

39. Wu M, Sherwin T, Brown WL, et al. Delivery of antisense oligonucleotides to leukemia cells by RNA bacteriophage capsids. Nanomedicine. 2005; 1: 67-76.

40. Guo Q, Shen N, Yuan K, et al. Caveolin-1 plays a critical role in host immunity against Klebsiella pneumoniae by regulating STAT5 and Akt activity. Eur J Immunol. 2012; 42: 1500-11.

41. Yuan K, Huang C, Fox J, et al. Elevated inflammatory response in caveoin-1-deficient mice with Pseudomonas aeruginosa infection is mediated by STAT3 protein and nuclear factor kappaB (NF-kappaB). J Biol Chem. 2011; 286: 21814-25.

42. Li G, Yuan K, Yan C, et al. 8-Oxoguanine-DNA glycosylase 1 deficiency modifies allergic airway inflammation by regulating STAT6 and IL-4 in cells and in mice. Free Radic Biol Med. 2012; 52: 392-401.

43. Kannan S, Pang H, Foster DC, et al. Human 8-oxoguanine DNA glycosylase increases resistance to hyperoxic cytotoxicity in lung epithelial cells and involvement with altered MAPK activity. Cell Death Differ. 2006; 13: 311-23.

44. Ye $\mathrm{Y}$, Wang $\mathrm{H}, \mathrm{Chu} \mathrm{JH}$, et al. Atractylenolide II induces G1 cell-cycle arrest and apoptosis in B16 melanoma cells. J Ethnopharmacol. 2011; 136: 279-82.

45. Wu M, Harvey KA, Ruzmetov N, et al. Omega-3 polyunsaturated fatty acids attenuate breast cancer growth through activation of a neutral sphingomyelinase-mediated pathway. Int J Cancer. 2005; 117: 340-8

46. Kannan $\mathrm{S}$, Huang $\mathrm{H}$, Seeger $\mathrm{D}$, et al. Alveolar epithelial type II cells activate alveolar macrophages and mitigate P. Aeruginosa infection. PLoS One. 2009; 4: $\mathrm{e} 4891$.

47. Wu M, Stockley PG, Martin WI, 2nd. An improved western blotting technique effectively reduces background. Electrophoresis. 2002; 23: 2373-6.

48. Wu M, Huang $\mathrm{H}$, Zhang $\mathrm{W}$, et al. Host DNA repair proteins in response to Pseudomonas aeruginosa in lung epithelial cells and in mice. Infect Immun. 2011; 79: 75-87.

49. Wu M, Audet A, Cusic J, et al. Broad DNA repair responses in neural injury are associated with activation of the IL-6 pathway in cholesterol-fed rabbits. J Neurochem. 2009; 111: 1011-21.

50. Hu B, Zhang LP, Chen XW, et al. Gold nanorod-covered kanamycin-loaded hollow SiO2 (HSKAu(rod)) nanocapsules for drug delivery and photothermal therapy on bacteria. Nanoscale. 2013; $5: 246-52$

51. Huang X, Li L, Liu T, et al. The shape effect of mesoporous silica NPs on biodistribution, clearance, and biocompatibility in vivo. ACS Nano. 2011; 5: 5390-9.

52. Chakravarthy KV, Davidson BA, Helinski JD, et al. Doxorubicin-conjugated quantum dots to target alveolar macrophages and inflammation. Nanomedicine. 2011; 7: 88-96.

53. Berg JM, Romoser AA, Figueroa DE, et al. Comparative cytological responses of lung epithelial and pleural mesothelial cells following in vitro exposure to nanoscale SiO2. Toxicol In Vitro. 2013; 27: 24-33.

54. Seidman DS, Moise J, Ergaz Z, et al. A new blue light-emitting phototherapy device: a prospective randomized controlled study. J Pediatr. 2000; $136 \cdot 771-4$.

55. Chang YS, Hwang JH, Kwon HN, et al. In vitro and in vivo efficacy of new blue light emitting diode phototherapy compared to conventional halogen quartz phototherapy for neonatal jaundice. J Korean Med Sci. 2005; 20: 61-4.

56. Tanaka K, Hashimoto H, Tachibana T, et al. Apoptosis in the small intestine of neonatal rat using blue light-emitting diode devices and conventional halogen-quartz devices in phototherapy. Pediatr Surg Int. 2008; 24: 837-42.
57. Sun J, Ramnath RD, Tamizhselvi R, et al. Neurokinin A engages neurokinin-1 receptor to induce NF-kappaB-dependent gene expression in murine macrophages: implications of ERK1/2 and PI 3-kinase/Akt pathways. Am J Physiol Cell Physiol. 2008; 295: C679-91.

58. Su JD, Yen JH, Li S, et al. 3',4'-didemethylnobiletin induces phase II detoxification gene expression and modulates PI3K/Akt signaling in PC12 cells. Free Radic Biol Med. 2012; 52: 126-41.

59. Li X, Zhou X, Ye Y, et al. Lyn regulates inflammatory responses in Klebsiella pneumoniae infection via the p38/NF-kappaB pathway. Eur J Immunol. 2013; doi: 10.1002/eji.201343972. [Epub ahead of print].

60. Berners-Price SJ. Activating platinum anticancer complexes with visible light. Angew Chem Int Ed Engl. 2011; 50: 804-5.

61. Oplander C, Deck A, Volkmar CM, et al. Mechanism and biological relevance of blue-light (420-453nm)-induced nonenzymatic nitric oxide generation from photolabile nitric oxide derivates in human skin in vitro and in vivo. Free Radic Biol Med. 2013; 65: 1363-77.

62. King A, Gottlieb E, Brooks DG, et al. Mitochondria-derived reactive oxygen species mediate blue light-induced death of retinal pigment epithelial cells. Photochem Photobiol. 2004; 79: 470-5.

63. Yang JH, Basinger SF, Gross RL, et al. Blue light-induced generation of reactive oxygen species in photoreceptor ellipsoids requires mitochondrial electron transport. Invest Ophthalmol Vis Sci. 2003; 44: 1312-9. 